\title{
Adherence to Therapeutic Regimen in Adults Patients Undergoing Hemodialysis: The Role of Demographic and Clinical Characteristics
}

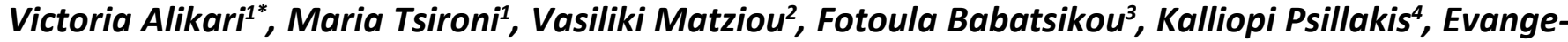 \\ los Fradelos ${ }^{1}$ and Sofia Zyga ${ }^{1}$
}

\author{
${ }^{1}$ Faculty of Human Movement and Quality of Life, Department of Nursing, University of Peloponnese, Greece \\ ${ }^{2}$ Department of Nursing, National \& Kapodistrian University of Athens, Greece \\ ${ }^{3}$ Department of Nursing, University of West Attica, Greece
}

${ }^{4}$ Renal Department, King's College Hospital, NHS Foundation, UK

*Corresponding author: Victoria Alikari, RN, MSc, PhD, Faculty of Human Movement and Quality of Life, Department of Nursing, University of Peloponnese, Sparta, Lakonia, Greece, Tel: +306936168825; +302105068066, E-mail: vicalikari@gmail.com

\begin{abstract}
Purpose: This study aimed to measure the adherence levels among patients undergoing hemodialysis and correlate the adherence levels with demographic and clinical characteristics.

Methods: To conduct the study, 350 patients undergoing hemodialysis completed the GR-Simplified-Medication Adherence Questionnaire-Hemodialysis (GR-SMAQ-HD). Demographic and clinical data were recorded. Statistical data analysis was performed using the IBM SPSS Statistics Version 19. Multiple linear regression test, stepwise method and logarithmic transformations were used. The level of statistical significance was set at up at 0.05 .

Results: The mean age of patients was 56.5 years $(\mathrm{SD}=$ 10.0 years). The whole score of GR-SMAQ-HD was 6.05 (SD $=1.54$ ) while for the dimensions of "Medication Adherence" was 3.01 (SD = 1.01), for "Attendance at HD Session" 1.75 $(\mathrm{SD}=0.51)$ and for "Diet/Fluid Restrictions" was $1.3(\mathrm{SD}=$ $0.70)$. The educational level and the absence of children were independently associated with the "Attendance at HD Session" ( $P=0.001$ and $P=0.007$, respectively). The daily number of pills was independently associated with "Attendance at HD Session" ( $P=0.020)$ and "Medication Adherence" score $(P=0.026)$. Vascular access site was independently associated with the total score of adherence scale $(P<0.001)$ and the "Medication Adherence" score $(P<0.001)$.
\end{abstract}

Conclusions: Adherence levels among patients undergoing hemodialysis are moderate while the role of demographic and clinical characteristics is crucial.

\section{Keywords}

Adherence, Clinical characteristics, Demographic characteristics, Hemodialysis

\section{Introduction}

It is widely accepted that End Stage Renal Disease (ESRD) entails significant changes in the patients' life. In addition, patients experience many changes that affect the outcome of the disease. Adherence to treatment regimen plays an indisputable role in the management of chronic kidney disease [1].

According to National Kidney Foundation-Kidney Disease Outcomes Quality Initiative (NKF-KDOQI) [2], non-adherence in hemodialysis (HD) includes: (a) Non-adherence to pharmaceutical treatment; (b) Omitting or shortening the time of HD session; (c) Excessive intake of fluids and foods containing potassium and phosphorus. ESRD under HD is a long-term illness that deprives patients of living a normal life. Factors, which influence HD patient adherence, vary and may be treatment-related, condition-related, health system-related or socioeconomic [3].

Most of the HD patients also experience other chronic diseases including hypertension, diabetes mellitus, cardiovascular disease, osteodystrophy requiring long-term medication [4]. The average of prescribed medications received by HD patients is $10-12$, while the average number of pills per day is 19 [5]. In addition, substitution of renal function through HD is associated with strong stressors such as attendance at HD session and diet/fluid restrictions. Non-adherence to

Citation: Alikari V, Tsironi M, Matziou V, Babatsikou F, Psillakis K, et al. (2018) Adherence to Therapeutic Regimen in Adults Patients Undergoing Hemodialysis: The Role of Demographic and Clinical Characteristics. Int Arch Nurs Health Care 4:096. doi.org/10.23937/2469-5823/1510096 Accepted: July 02, 2018: Published: July 04, 2018

Copyright: (c) 2018 Alikari V, et al. This is an open-access article distributed under the terms of the Creative Commons Attribution License, which permits unrestricted use, distribution, and reproduction in any medium, provided the original author and source are credited. 
diet restrictions can lead to chronically elevated levels of potassium or phosphorus levels which, in turn, play a major role in the onset of cardiac arrest or renal osteodystrophy, respectively. Moreover, shortening or skipping an HD session can reduce the adequacy of HD and increase the risk of death.

For the above reasons, the need for early identification and assessment of non-adherence levels among HD patients is vital. However, given the complexity of the pathogenicity of adherence and the lack of multidimensional tools, an effective intervention by nephrology nurses is difficult. Hence, nurses and health-care professionals of hemodialysis units and nephrology clinics should be alert to detection of non-adherence in order to improve the care plan and help patients develop contingency strategies [6]. Because of their contact with HD patients, nephrology nurses could help improve adherence levels by creating a relationship of trust with patients through their approach.

According to studies, factors of patient non-adherence vary [7]. Sabaté (2003) has ranked potential non-adherence factors in five categories: Treatment-related, disease-related, health-system related and finally, socio-economic [8]. More specifically, in the international literature the causes of non-compliance may be the beliefs of the patient [9], the poor relationship between a healthcare professional and a patient [10] the personality of the patient [11], the educational level or economic reasons [12]. Most of these studies agree that all potential determinants should be considered in order to improve the patient's ability to follow the treatment regimen.

In adult patients undergoing HD, demographic factors that may affect adherence to medication, diet and fluid intake, include young age [13-15], black race [16-18], female $[16,18,19]$ absence of family support $[12,20,21]$, and low educational level $[22,23]$. Most of these studies agree that all potential determinants should be considered in order to improve the HD patients' ability to follow the treatment regimen.

Despite the extended research on the topic of adherence, our knowledge on adherence among HD patients is still limited. Thus, the aim of the study was to examine the levels of adherence in ESRD patients undergoing HD. This study is the first one exploring the adherence levels in Greek HD patients. Based on prior research findings highlighting the effect of demographic and clinical characteristics on patient adherence, it was decided to investigate, also, the association between these variables and adherence.

The research hypothesis of this study was that adherence levels are low among HD patients while it is expected an important impact of demographic on the clinical characteristics.

\section{Methods}

\section{Design}

This is a descriptive and analytic study. Patients were from three hemodialysis centers in the area of Athens and Peloponnese region: (i) "latriko Therapeftirio Iliou Medifil A.E." (Athens), (ii) General Hospital of Athens "G. Gennimatas" (Athens) and, (iii) Panarkadiko Hospital of Tripolis "Evaggelistria" (Peloponnese region). All 371 patients on maintenance HD from these Hemodialysis Units were asked to participate in this study. The inclusion criteria were: (a) Aged > 18 years; (b) Undergoing hemodialysis for at least 6 months and (c) Ability to write and read the Greek language. Patients with history of mental illness, cognition problems, serious mobility or eye problem were excluded from the study. Finally, 350 patients met the criteria (response rate $94.3 \%$ ). The study was conducted from June 2017-August 2017.

\section{Measurements}

Researchers provided the questionnaire to patients during HD session. A self-administered questionnaire included demographic and clinical variables (age, gender, marital status, having children, educational level, years on HD, vascular access site, co-existing diseases, the daily number of pills) was given followed by the GR-Simplified Medication Adherence Questionnaire-Hemodialysis (GR-SMAQ-HD). The questionnaire used had been validated for the respective Greek HD population [18]. As GR-SMAQ-HD is the only one tool for subjective measuring of adherence among Greek HD patients, an effort was performed in order to measure adherence using this scale. The questionnaire consists of eight items exploring the three dimensions of adherence in hemodialysis: (i) "Medication Adherence" (items 1-4), (ii) "Attendance at Hemodialysis Session" (items 5 \& 6) and "Diet/Fluid Restrictions" (items $7 \& 8$ ). Three of the items are dichotomous (Yes/No) while five are scored on a 5 point Likert-type scale. The internal consistency of the scale has been studied (Cronbach's Alpha 0.751) [24]. The score ranges from 0-8. Higher scores indicate higher adherence to HD regimen. This is the first time GR-SMAQ-HD is used in Greek HD patients.

\section{Ethical considerations}

The current study was approved by the scientific councils of the hospitals and Hellenic Data Protection Authority (Approval number $\Gamma \mathrm{N} / \mathrm{E}=/ 240-3 / 11-02-2016$ ). Patients were informed about the aim of the study, the anonymity and the safety of the data and that they can quit the study whenever they wish. Informed consent was obtained.

\section{Statistical analysis}

Quantitative variables were described using the means, standard deviations, median and interquartile ranges. Qualitative variables were described using the 
absolute $(\mathrm{N})$ and relative (\%) frequencies. Linear regression analysis by stepwise was used to find independent factors associated with the study scale from which dependency factors $(\beta)$ and their standard errors (SE) occurred.

\section{Results}

In total, 350 patients undergoing hemodialysis participated in this study. The mean age of patients was 56.5 years ( $S D=10.0$ years). Analytically, sociodemographic and clinical characteristics of patients are presented in Table 1.

\section{Descriptive statistics of adherence}

The total score of all participants' adherence ranged

Table 1: Sociodemographic and clinical characteristics of patients $(\mathrm{N}=350)$.

\begin{tabular}{|c|c|c|c|}
\hline & & $\mathbf{N}$ & $\%$ \\
\hline \multicolumn{2}{|c|}{ Age, Mean (SDa) } & $56.5(10.0)$ & \\
\hline \multirow[t]{2}{*}{ Gender } & Male & 230 & 65.7 \\
\hline & Female & 118 & 33.7 \\
\hline \multirow[t]{4}{*}{ Marital Status } & Unmarried & 79 & 22.5 \\
\hline & Married & 194 & 55.4 \\
\hline & Divorced & 30 & 7.71 \\
\hline & Widows & 47 & 13.4 \\
\hline \multirow[t]{2}{*}{ Children } & No & 99 & 28.2 \\
\hline & Yes & 250 & 71.4 \\
\hline \multirow[t]{2}{*}{ Living alone } & Yes & 56 & 16.0 \\
\hline & No & 294 & 84.0 \\
\hline \multirow{6}{*}{$\begin{array}{l}\text { Educational } \\
\text { level }\end{array}$} & Illiterate & 22 & 6.2 \\
\hline & Primary School & 114 & 32.5 \\
\hline & Secondary School & 78 & 22.2 \\
\hline & High School & 79 & 22.5 \\
\hline & University Student & 12 & 3.4 \\
\hline & University Graduate & 44 & 12.5 \\
\hline \multirow[t]{6}{*}{ Employment } & Unemployed & 55 & 15.7 \\
\hline & Household & 39 & 11.1 \\
\hline & Self-employed & 25 & 7.1 \\
\hline & Private employee & 19 & 5.4 \\
\hline & State employee & 12 & 3.4 \\
\hline & Retired & 199 & 56.8 \\
\hline \multirow{5}{*}{$\begin{array}{l}\text { Co-existing } \\
\text { diseases }\end{array}$} & Diabetes mellitus & 79 & 22.5 \\
\hline & Hypertension & 93 & 26.5 \\
\hline & Glomerulonephritis & 65 & 18.5 \\
\hline & Polycystic disease & 40 & 11.4 \\
\hline & Other & 70 & 20.0 \\
\hline \multicolumn{2}{|c|}{ Years on Hemodialysis, Mean $\left(\mathrm{SD}^{\mathrm{a}}\right)$} & \multicolumn{2}{|l|}{$6.5(5.3)$} \\
\hline \multicolumn{2}{|c|}{ Daily number of pills, Mean (SD $\left.{ }^{a}\right)$} & \multicolumn{2}{|l|}{$7.1(5.4)$} \\
\hline \multirow{3}{*}{$\begin{array}{l}\text { Vascular } \\
\text { access site }\end{array}$} & Fistula & 226 & 64.5 \\
\hline & Graft & 49 & 14.0 \\
\hline & Central Venous Catheter & 74 & 21.1 \\
\hline
\end{tabular}

from 1-8 (Mean $=6.05, S D=1.54)$. The following table gives the participants' scores on adherence dimensions. Means, standard deviations, minimum and maximum scores of all dimensions of adherence are presented in Table 2.

\section{Multiple linear regression}

Then, a multifactorial linear regression was performed. The overall adherence score, the score of "Medication Adherence", the score of "Attendance at HD Session" and "Diet/Fluid Restrictions" were used as dependent variables. The demographic and clinical data of the participants was used as independent variables. Using the stepwise method and using logarithmic transformations, the results of the table below were found (Table 3).

The educational level was independently associated with the total adherence score of participants, with the "Medication Adherence" score and "Attendance at HD Session" scores. Educational level and years on HD was independently associated with the adherence to "Diet/Fluid restrictions". Vascular access site was independently associated with the total adherence score of participants and with the "Medication Adherence" score. The daily number of pills was independently associated with the "Medication Adherence" score and "Attendance at HD session" score while the having children was independently associated with the "Attendance at HD session" score.

\section{Discussion}

This study was carried out in the broad area of Athens and Peloponnese region and aimed to assess the adherence among 350 patients on maintenance HD. It, also, targeted to explore the relationship between demographic and clinical characteristics of patients with adherence levels.

The mean score of the whole adherence scale was 6.05 (SD = 1.54). According to our findings, the low levels of adherence are common among HD patients and are affected by several demographic and clinical variables.

In our study an important aspect which affected the adherence was the educational level. This study found that high school graduates had significantly higher score in all domains of adherence in comparison to the illiterate and primary school graduates. Similarly, University students and graduates had a significantly higher score compared to the illiterate and primary school students.

Table 2: Mean values, standard deviations and minimum and maximum scores of patients' adherence $(\mathrm{N}=350)$.

\begin{tabular}{|l|l|l|l|l|}
\hline & Min. & Max. & Mean (SD) & Median (IR $)$ \\
\hline Total Score of GR-SMAQ-HD & 1 & 8 & $6.05(1.54)$ & $7(5-8)$ \\
\hline Medication Adherence & 0 & 4 & $3.01(1.01)$ & $3(2-4)$ \\
\hline Attendance at HD Session & 0 & 2 & $1.75(0.51)$ & $2(2-2)$ \\
\hline Diet/Fluid Restrictions & 0 & 2 & $1.3(0.70)$ & $2(1-2)$ \\
\hline
\end{tabular}

Notes: a Standard Deviation; ${ }^{b}$ Interquartile Range. 
Table 3: Multifactorial linear regression.

\begin{tabular}{|c|c|c|c|c|}
\hline & & $\mathbf{B}^{\mathbf{a}}$ & SE $^{\mathrm{b}}$ & $\mathbf{p}$ \\
\hline \multicolumn{5}{|c|}{ Total Score of GR-SMAQ-HD } \\
\hline \multirow[t]{3}{*}{ Educational level } & \multicolumn{4}{|l|}{ Illiterate/Primary School (reference group) } \\
\hline & Secondary/High School & 0.08 & 0.02 & $<0.001$ \\
\hline & University Student/University Graduate & 0.10 & 0.02 & $<0.001$ \\
\hline \multirow[t]{3}{*}{ Vascular access site } & \multicolumn{4}{|l|}{ Fistula (reference group) } \\
\hline & Graft & 0.02 & 0.02 & 0.433 \\
\hline & Central Venous Catheter & -0.07 & 0.02 & $<0.001$ \\
\hline \multicolumn{5}{|l|}{ Medication Adherence } \\
\hline \multirow[t]{3}{*}{ Educational level } & \multicolumn{4}{|l|}{ Illiterate/Primary School (reference group) } \\
\hline & Secondary/High School & 0.08 & 0.02 & $<0.001$ \\
\hline & University Student/University Graduate & 0.10 & 0.02 & $<0.001$ \\
\hline \multirow[t]{3}{*}{ Vascular access site } & Fistula (reference group) & & & \\
\hline & Graft & 0.02 & 0.02 & 0.603 \\
\hline & Central Venous Catheter & -0.07 & 0.02 & $<0.001$ \\
\hline Daily number of pills & & -0.004 & 0.002 & 0.026 \\
\hline \multicolumn{5}{|c|}{ Attendance at HD Session } \\
\hline Daily number of pills & & 0.004 & 0.002 & 0.020 \\
\hline \multirow[t]{3}{*}{ Educational level } & Illiterate/Primary School (reference group) & & & \\
\hline & Secondary/High School & 0.05 & 0.01 & 0.001 \\
\hline & University Student/University Graduate & 0.06 & 0.02 & 0.003 \\
\hline \multirow[t]{2}{*}{ Having Children } & No (reference group) & & & \\
\hline & Yes & 0.04 & 0.01 & 0.007 \\
\hline \multicolumn{5}{|l|}{ Diet/Fluid Restrictions } \\
\hline \multirow[t]{3}{*}{ Educational level } & Illiterate/Primary School (reference group) & & & \\
\hline & Secondary/High School & 0.07 & 0.02 & 0.001 \\
\hline & University Student/University Graduate & 0.03 & 0.03 & 0.202 \\
\hline Years on HD & & 0.004 & 0.001 & 0.001 \\
\hline
\end{tabular}

Several studies have found that a high level of education can lead to better adherence rates $[16,17,22]$. The higher the educational level, the higher the level of knowledge and adherence [14]. Some researchers suggest that a patient with a high educational level can more easily understand the usefulness of the therapy [14] while other authors [25] report that it is difficult for high educational level patients to comply due to employment and occupational obligations.

We, also, found that the longer the duration (years) on HD, the higher the adherence of level they had. However, this finding contrasts with the results of other studies $[15,26]$ which refer that the longevity of HD may be significantly associated with non-adherence. Moreover, HD patients who are under dialysis for many years have great knowledge on HD and, therefore, are more likely to be adherent than the new ones. In view of this, health professionals of HD Units should identify the knowledge base of each subject.

Participants using a central venous catheter to undergo hemodialysis had a significantly lower score compared to the participants who performed hemodialysis with a graft. This finding may be correlated to the previous one as the new HD patients of our sample (and therefore the less compliant) initiate dialysis using a central venous catheter while the graft is usually the last choice for vascular access.
The mean number of pills in the total of 350 patients in the sample was 7.1. This number appears to be lower than the overall average (10-12 pills) mentioned in the literature [27]. Despite all this, the number of pills is a predictor of adherence in this study. In particular, the higher burden of pills, the lower adherence scores both to "Medication Adherence" and "Attendance at HD Session". A study related to the effect of the number of pills on adherence reported similar results [28] while another study conducted in Italy using questionnaires noted that the larger the number of pills the lower the adherence level [29]. A study [30] using the Simplified Medication Adherence Questionnaire reported that of the 165 dialysis patients, $40 \%$ had low compliance with medication (21\% in phosphorus and $13 \%$ in antihypertensive agents). Patients had selective non-adherence to phosphate binders, as these should be taken during meals, at least 3 times a day. Therefore, they coincide with working hours or the social life of patients, especially young [30]. The contribution of various drugs to the daily pill burden in hemodialysis patients has not been investigated so far. The serum phosphate level has now been shown to be an independent factor of death risk [31]. Clinicians' experience suggests that phosphate binders are probably the largest factor in the daily pills number [32].

Participants with children had a significantly higher score compared to participants without children. The 
marital status and family support (existence of children) seems to be positively correlated with the adherence levels as in previous studies [33,34]. However, marital status was not found to be correlated to patient adherence in two studies $[35,36]$. Lack of social/family support is sometimes a barrier to adherence to $\mathrm{HD}$ regimen according to the literature [23]. In North America, patients without family support were more likely to omit or shorten the duration of HD session [20]. Therefore, social support can affect positive results and is a link between hemodialysis patients and adherence to treatment [37].

At this point, it is important to emphasize that the items of GR-SMAQ-HD don't record the cases of adherence/non-adherence due to clinical complications but only those due to personal initiative of the patient.

GR-SMAQ-HD is the modified version of GR-SMAQ [24] which has been translated in Greek language and culturally adapted for Greek lung cancer patients [38]. The first version of SMAQ was used to measure adherence levels on the dimension of medication among HIV patients [39].

Regarding the limitations of the study it is noted that that interference of external variables (interruption by others, room temperature, noise level and fatigue of the participants and persons with underlying disease), probably influenced the answers of respondents. Results cannot be generalized for all Greek patients undergoing HD as the study was conducted in Athens and Peloponnese region even if these areas are two major geographic regions of Greece. Therefore, more studies using the GR-SMAQ-HD are needed.

This study was an attempt to assess for first time adherence among Greek HD patients using subjective measures. Future studies could combine subjective with objective measures (pill count, laboratory tests). Due to the lack of a world guideline on adherence measures of HD patients, there is a need for research on which tool (subjective, objective or a combination of them), is the most suitable for this special target group.

\section{Conclusion}

According to the findings of this study, adherence levels among HD patients are moderate while the role of demographic and clinical characteristics is crucial. Results of this study could be used in Hemodialysis Units implementing programs focused on the investigation of adherence levels, patients' behavior and factors of non-adherence. Therefore, health care professionals of HD Units should be aware of the non-adherence issues.

\section{Acknowledgments}

The authors would like to acknowledge the patients undergoing hemodialysis who participated in this study and the Scientific Councils of the Hospitals.

\section{Conflict of Interest}

None declared.

\section{References}

1. Karam SN, Mohammad AB, Moutaz WS, Samah WAL, Waleed MS, et al. (2017) Treatment adherence and perception in patients on maintenance hemodialysis: $A$ cross - sectional study from Palestine. BMC Nephrol 18: 178.

2. Estrella MM, Jaar, BG, Cavanaugh KL, Chester HF, Perazella MA, et al. (2013) Perceptions and use of the national kidney foundation KDOQI guidelines: A survey of U.S. renal healthcare providers. BMC Nephrol 14: 230.

3. Chironda G, Bhengu B (2016) Contributing factors to non-adherence among Chronic Kidney Disease (CKD) patients: A systematic review of literature. Med Clin Rev 2: 29.

4. Levey AS, Coresh J (2012) Chronic kidney disease. Lancet 379: 165-180.

5. Ghimire S, Castelino RL, Lioufas NM, Peterson GM, Zaidi ST (2015) Nonadherence to medication therapy in haemodialysis patients: A systematic review. PLoS One 10: e0144119.

6. Davison I, Cooke S (2015) How nurses' attitudes and actions can influence shared care. J Ren Care 41: 96-103.

7. Ginieri-Coccossis $M$, Theofilou $P$, Synodinou $C$, Tomaras V, Soldatos C (2008) Quality of life, mental health and health beliefs in haemodialysis and peritoneal dialysis patients: Investigating differences in early and later years of current treatment. BMC Nephrol 9: 14.

8. Sabaté E (2003) Adherence to long-term therapies. World Health Organization, Geneva.

9. Covic A, Rastogi A (2013) Hyperphosphatemia in patients with ESRD: Assessing the current evidence linking outcomes with treatment adherence. BMC Nephrol 14: 153.

10. Martins MT, Silva LF, Kraychete A, Reis D, Dias L, et al. (2013) Potentially modifiable factors associated with non-adherence to phosphate binder use in patients on hemodialysis. BMC Nephrol 14: 208.

11. Theofilou P (2013) The effect of sociodemographic features and beliefs about medicines on adherence to chronic kidney disease treatment. International Journal of Caring Sciences 6: 188-194.

12. Kauric-Klein Z (2013) Predictors of nonadherence with blood pressure regimens in hemodialysis. Patient Prefer Adherence 7: 973-980.

13. Gordon EJ, Leon JB, Sehgal AR (2003) Why are hemodialysis treatments shortened and skipped? Development of a taxonomy and relationship to patient subgroups. Nephrol Nurs J 30: 209-217.

14. Baraz S, Parvardeh S, Mohammadi E, Broumand B (2010) Dietary and fluid compliance: An educational intervention for patients having haemodialysis. J Adv Nurs 66: 60-68.

15. Chan YM, Zalilah MS, Hii SZ (2012) Determinants of compliance behaviours among patients undergoing haemodialysis in Malaysia. PLoS One 7: e41362.

16. Saran R, Bragg-Gresham JL, Rayner HC, Goodkin DA, Keen ML, et al. (2003) Non-adherence in hemodialysis: Associations with mortality, hospitalization, and practice patterns in the DOPPS. Kidney Int 64: 254-262.

17. Unruh ML, Evans IV, Fink NE, Powe NR, Meyer KB (2005) Skipped treatments, markers of nutritional non-adherence, and survival among incident haemodialysis patients. Am J Kidney Dis 46: 1107-1116. 
18. Tijerina MS (2009) Mexican American women's adherence to hemodialysis treatment: A social constructivist perspective. Soc Work 54: 232-242.

19. Barnett T, Li Yoong T, Pinikahana J, Si-Yen (2008) Fluid compliance among patients having haemodialysis: Can an educational programme make a difference? J Adv Nurs 61: 300-306.

20. Untas A, Thumma J, Rascle N, Rayner H, Mapes D, et al. (2011) The associations of social support and other psychosocial factors with mortality and quality of life in the dialysis outcomes and practice patterns study. Clin J Am Soc Nephrol 6: 142-152.

21. Smith $\mathrm{K}$, Coston M, Glock K, Elasy TA, Wallston KA, et al. (2010) Patient perspectives on fluid management in chronic hemodialysis. J Rel Nutr 20: 334-341.

22. Bland RJ, Cottrell R, Guyler L (2008) Medication compliance of haemodialysis patients and factors contributing to non-compliance. Dial Transplant 37: 174-178.

23. Kugler C, Maeding I, Russell CL (2011) Non-adherence in patients on chronic hemodialysis: An international comparison study. J Nephrol 24: 366-375.

24. Alikari V, Matziou V, Tsironi M, Kollia N, Theofilou P, et al. (2017) A modified version of the Greek Simplified Medication Adherence Questionnaire for hemodialysis patients. Health Psychol Res 5: 6647.

25. Grierson J (2000) HIV futures II: The health and well-being of people with HIVIAIDS in Australia. Melbourne: Australian Research Centre in Sex, Health \& Society, La Trobe University.

26. O'Connor SM, Jardine AG, Millar K (2008) The prediction of self-care behaviors in end-stage renal disease patients using Leventhal's Self-Regulatory Model. J Psychosom Res 65: 191-200.

27. Manley HJ, Garvin CG, Drayer DK, Reid GM, Bender WL, et al. (2004) Medication prescribing patterns in ambulatory haemodialysis patients: Comparisons of USRDS to a large not-for-profit dialysis provider. Nephrol Dial Transplant 19: 1842-1848.

28. Chiu YW, Teitelbaum I, Misra M, de Leon EM, Adzize T, et al. (2009) Pill burden, adherence, hyperphosphatemia, and quality of life in maintenance dialysis patients. Clin $\mathrm{J} \mathrm{Am}$ Soc Nephrol 4: 1089-1096.
29. Neri L, Martini A, Andreucci VE, Gallieni M, Rey LA, et al. (2011) Regimen complexity and prescription adherence in dialysis patients. Am J Nephrol 34: 71-76.

30. Arenas MD, Malek T, Gil MT, Moledous A, Alvarez-Ude F, et al. (2010) Challenge of phosphorus control in hemodialysis patients: A problem of adherence? J Nephrol 23: 525534.

31. Kalpakian MA, Mehrotra R (2007) Vascular calcification and disordered mineral metabolism in dialysis patients. Semin Dial 20: 139-143.

32. Karamanidou C, Clatworthy J, Weinman J, Horne R (2008) A systematic review of the prevalence and determinants of non-adherence to phosphate binding medication in patients with end-stage renal disease. BMC Nephrol 9: 2.

33. Ahrari S, Moshki M, Bahrami M (2014) The relationship between social support and adherence of dietary and fluids restrictions among hemodialysis patients in Iran. J Caring Sci 3: 11-19.

34. Kara B, Caglar K, Kilic S (2007) Nonadherence of with diet and fluids restrictions and perceived social support in patients receiving hemodialysis. J Nurs Scholarsh 39: 243248.

35. Ghods A, Nasrollahzadeh S (2003) Noncompliance with immunosuppressive medications after renal transplantation. Exp Clin Transplant 1: 39-47.

36. Spikmans FJ, Brug J, Doven MM, Kruizenga HM, Hofsteenge $\mathrm{GH}$, et al. (2003) Why do diabetic patients not attend appointments with their dietitian? J Hum Nutr Diet 16: 151-158.

37. Alikari V, Fradelos E, Zyga S (2015) Family support, social and demographic correlations of non-adherence among haemodialysis patients. American Journal of Nursing 4: 6065.

38. Theofilou P (2012) Results from the translation and cultural adaptation of the Greek Simplified Medication Adherence Questionnaire (GR-SMAQ) in patients with lung cancer. Journal of Clinical Trials S1: 001.

39. Knobel H, Alonso J, Casado JL, Collazos J, González J, et al. (2002) Validation of a simplified medication adherence questionnaire in a large cohort of HIV-infected patients: The GEEMA Study. AIDS 16: 605-613. 